Bol. Acad. peru. leng. 52. 2011 (181-192)

\title{
AQUÍ SE ESCRIBE EN ESPAÑOL: REFLEXIONES SOBRE LA LITERATURA DE CHICAGO
}

\author{
José Castro Urioste
}

Fecha de recepción:

$22 / 10 / 2011$

Fecha de aceptación:

$26 / 10 / 2011$

La producción de la literatura en castellano en los Estados Unidos no es reciente. Es un proceso histórico, cuyo inicio puede rastrearse desde la llegada del conquistador Juan de Oñate a lo que hoy en día es Nuevo México. Con Oñate se introduce el español, como también el teatro europeo y -durante el periodo de la colonia la producción literaria en nuestra lengua- se intensifica en el suroeste de los Estados Unidos, alcanzando un punto culminante en el año 1848. En esta fecha, y a partir del Tratado de Guadalupe-Hidalgo, el español pierde su posición de lengua dominante y se transforma en la lengua de la resistencia cultural. Se desarrolla así una intensa labor periodística y en estos medios de prensa se publican también cuentos y poemas. Otro momento culminante en el proceso histórico de la producción literaria en castellano en los Estados Unidos es el año 1898. Tal fecha puede ser simbólica para marcar no solo el fin de un siglo sino el inicio del otro. Es el fin del Imperio Español -expresado enfáticamente por la Generación del 98- como la advertencia de la generación modernista ante el surgimiento del Imperio Norteamericano. En este cambio de siglo, una generación de escritores 
radicados en Estados Unidos buscó crear a partir de sus textos en español una imagen de identidad mexicoamericana ${ }^{1}$.

Los sucesos históricos del siglo XX en América Latina y en España produjeron nuevas olas migratorias que hicieron que la producción literaria en español en Estados Unidos fuera más rica y compleja. El periodo de la Revolución Mexicana, la Guerra Civil Española, la Revolución Cubana, el caso específico de Puerto Rico, las dictaduras fascistas en el Cono Sur, las propuestas neoliberales que trajeron severas crisis económicas, hicieron que nuevas oleadas de inmigrantes de distintas condiciones socio-económicas, con una variedad de distintos niveles educativos, y con posiciones ideológicas no solo diferentes sino hasta encontradas, llegaran a los Estados Unidos. Este cambio demográfico generó un intenso proceso de latinización de las ciudades norteamericanas. Siempre se ha mencionado que tal latinización se ha desarrollado en las grandes ciudades estadounidenses como Nueva York, Miami, Los Ángeles, Chicago. Sin embargo, áreas menos pobladas de Estados Unidos también están siendo parte de esta latinización. Pienso, por ejemplo, en el noroeste de Indiana en la cual se produce en las primeras décadas del siglo $\mathrm{XX}$ un periodismo y un teatro en español.

En el caso particular de Chicago se viene desarrollando un intenso proceso de latinización que la ha convertido en una de las ciudades norteamericanas con mayor población hispano parlante. El censo de 2000 indica que en el condado de County -que abarca la ciudad de Chicago y sus alrededores- el $19.99 \%$ de los habitantes son latinos. Dentro de este grupo la comunidad más numerosa es la mexicana ( $14.6 \%$ de la población total de la ciudad). A esta le sigue la puertorriqueña $(2.4 \%)$, la cubana $(0.2 \%)$ y un $2.6 \%$ compuesto por inmigrantes latinoamericanos de otras regiones. ${ }^{2}$ Como consecuencia de

1 Martin Rodríguez, Manuel. “'Por herencia una red de agujeros': hacia una historia cultural de la literatura chicana”. La Palabra y el Hombre 124 (2002), véanse especialmente pp 7-20.

2 Asimismo, el censo de 2000 indica que el $21.7 \%$ de los habitantes de la ciudad de Chicago no son nacidos en Estados Unidos; de este grupo 56.3\% proviene de América Latina. Finalmente, en el estado de Illinois la población latina se incrementó de 1990 a 2000. 
este proceso se han organizado actividades y espacios culturales. Entre otros ejemplos se puede citar la intensa agenda del Museo Mexicano de Bellas Artes - ubicado en Pilsen, uno de los barrios mexicanos-, el Centro Cultural Latino de Chicago, la agenda del Instituto Cervantes, la circulación de varios periódicos en castellano como de revistas literarias, la aparición de numerosas bandas de rock compuestas por jóvenes nacidos en Estados Unidos, pero con herencia latinoamericana que prefieren cantar en la lengua de sus progenitores, el surgimiento -a partir de los noventa- de un conjunto de grupos teatrales latinos, los cuales funcionan con diferentes grados de organización. Cabe indicar que tal proceso de latinización no implica una posición ideológica homogénea. Muy por el contrario, en determinados casos se plantean perspectivas completamente enfrentadas: por ejemplo, determinados artistas latinos de Chicago rechazan el proyecto del Museo Mexicano de Bellas Artes (el cual funciona con apoyo financiero de fundaciones), optando por una posición mucho más radical. ${ }^{3}$

En el caso de la literatura latina en Chicago también se puede trazar etapas. Según Marc Zimmerman, es posible distinguir tres grandes momentos dentro de este proceso histórico-literario. El primero de ellos se inicia con la migración que surge durante el periodo de la Revolución Mexicana y puede ser considerada como la expresión pionera mexicana que empleo géneros de la literatura popular como los corridos y la poesía declamatoria. Un segundo momento se da con la expresión literaria de los hijos de aquellos inmigrantes. Se trata de textos inglés y en ellos se expresa la visión de sujetos que se reconocen como una minoría dentro de los Estados Unidos. En este grupo puede ubicarse la obra de una escritora como Sandra Cisneros. Finalmente se halla la obra literaria de los inmigrantes que llegaron a partir de los setenta que son parte de la migración generada por las dictaduras fascistas y la crisis económica generada por la implantación de políticas neoliberales. ${ }^{4}$

3 Castro Urioste, José. "Más allá del fin de la historia: una conversación con Marc Zimmerman. Pie de página 1 (2002) 3-6.

4 Zimmerman, Marc. "La literatura en español en Chicago". Contratiempo, 25, 2005, p. 10.

Bol. Acad. peru. leng. 52(52), 2011 
La producción y el desarrollo de la literatura en castellano de Chicago también están vinculados al lugar que esta lengua ocupa en la ciudad, donde el idioma dominante es el inglés y a la función que posee (o ha tenido) el acto de escribir obstinadamente en castellano en esta urbe. Inicialmente, el castellano estuvo relegado al espacio privado, al mundo de la casa y de la familia. Abundan los testimonios (y no de hace muchas décadas atrás) de niños latinos que eran castigados por hablar en castellano en las escuelas. Esto, evidentemente, es un ejemplo que la lengua estaba bajo la prohibición de cruzar el límite del hogar, del espacio privado.

Hoy en día esa tendencia ha variado. El castellano ha dejado de ser únicamente la lengua de la casa debido, en parte, a la presión de las políticas sobre el bilingüismo, y también en parte, porque la empresas han visto al latino como sujeto de consumo (en otras palabras, hay un mercado latino y se considera que es más persuasivo acercarse a este en nuestra lengua), y, a su vez, debido a que el número de latinos representa votos potenciales para los políticos de turno. En todo caso, el castellano ha dejado de ser una lengua circunscrita a la esfera de lo privado para transformarse en una de dominio público.

En este proceso de transformación, cabe preguntarse qué lugar ocupa el trabajo de la generación más reciente de escritores. Me parece -y esto no deja de ser una hipótesis- que este grupo de escritores, por medio de sus talleres, de sus publicaciones, de las presentaciones de sus libros, de sus recitales, son los pioneros en hacer que el castellano no estuviera restringido a la esfera de lo privado. Estos escritores marcaron, a través de su producción literaria, la pauta para que nuestra lengua posea también un lugar en el espacio público (así sea mínimamente, o clandestinamente) en la ciudad de Chicago. Más aún: estos escritores hicieron que nuestra lengua tuviera un lugar en el orden de lo público no por razones de búsqueda de un mercado ni para conquistar un voto, sino como defensa de una cultura.

Asimismo, al analizar la literatura en castellano de Chicago, debo referirme al aporte pionero de John Barry. Frecuentemente, se 
menciona al crítico literario como aquel que forja una literatura. Es el crítico quien le da sus límites, sus características, quien sistematiza un conjunto de textos. El trabajo de Barry (tanto sus dos antologías Voces en el viento y En el ojo del viento, como el conjunto de artículos de crítica literaria que publicó en diversas revistas) trata, precisamente, de la construcción de un corpus de la literatura en castellano de Chicago. Barry buscó forjar un lugar para esa literatura tanto dentro de las letras en castellano, como dentro de la cultura norteamericana (de allí que su última antología sea bilingüe). La poeta argentina Leda Schiavo, quien estuvo radicada en Chicago por varias décadas, sostenía que Barry “...tuvo una fe indestructible en nosotros mismos, los que escribíamos en español en Chicago [...]. Hasta tenía más fe que nosotros mismos" 5 .

La pregunta que surge es qué características posee el corpus literario al que se refiere John Barry. Según Barry los escritores de este grupo, a diferencia de las generaciones anteriores que provenían fundamentalmente de México, proceden de distintos países de América Latina. Es un grupo formalmente más educado, con una posición económica más cómoda y que se desempeña en una diversidad de oficios (como profesores, técnicos, comerciantes, traductores, entre otros empleos). Todos estos escritores llegan a Chicago en su edad adulta y su lengua natal es el castellano. En todos ellos existe "un deseo": el de escribir, y escribir significa hacerlo en castellano, a pesar del bilingüismo que algunos llegan a adquirir. El ejemplo más claro es el de León Leiva, quien inicialmente publica poemas en inglés, pero luego desarrolla su obra poética y narrativa en castellano. Detrás de este "deseo" de escribir al que se refiere Barry, se instala la herencia del profesionalismo de la literatura que reclamaron las generaciones anteriores de escritores latinoamericanos ${ }^{6}$.

5 Schiavo, Leda. "Se nos ha muerto, como del rayo, John Barry, con quien tanto queríamos". Contratiempo, 6, 2003, p. 23.

6 Barry, John. "Persistencia de la memoria: prosa en español desde Chicago". Pie de página, 2, 2004, p. 54. 
Este grupo de escritores se aglutinó en talleres y luego en revistas literarias. A partir de estas actividades John Barry observó la formación de un movimiento literario que se iba desarrollando y que era desconocido en los países hispanoparlantes. Asimismo, Barry consideraba que el grupo se hallaba en proceso de transición de una etapa embrionaria a una de madurez plena. Tal observación se sustentaba en la transformación de las revistas literarias. Las primeras - Cardinal (1983), tres Américas (1990-1996), Fe de erratas (1992-1995), Abrapalabra (1995)- enfatizaban implícita y explícitamente el deseo de mantener vínculos con los países donde habían nacido los escritores ${ }^{7}$. En las publicaciones posteriores, el énfasis se otorgaba a las circunstancias presentes y a la realidad que vivían los escritores más que a la nostalgia por sus países de origen ${ }^{8}$.

En cuanto al aspecto formal, Barry consideraba que el grupo era heterogéneo y que existía en él el cultivo de una amplia diversidad de formas narrativas, desde cuentos fantásticos a realistas, desde relatos regionalistas a cosmopolitas. En tal sentido, el uso del lenguaje también poseía la misma característica, la diversidad: es posible encontrar relatos que imitan los modos de hablar de los pueblos y ciudades latinoamericanas, hasta textos en los que se refleja el contacto con el inglés. Finalmente, Barry creía en el valor estético de la producción literaria en castellano que se desarrollaba en Chicago. Sin embargo, enfatizaba que solo una valoración realizada fuera de la ciudad podría otorgarle un lugar y un reconocimiento a esa producción literaria ${ }^{9}$.

7 Barry, John. "Escritura y escritos en español en Chicago". Contratiempo, 32, 2006, p. 8.

8 Una breve historia sobre las revistas literarias de Chicago se encuentra en el artículo de Ricardo Armijo "Historia silvestre de las revista literarias en español de Chicago" Pie de página, 1, 2002, pp. 23-27. Armijo coincide con esta evolución de la revistas, vinculada a las características del grupo: “(...) si bien los inmigrantes vivimos diariamente la diáspora a nivel nacional, la formación [...] de grupos en los distintos centros urbanos ha dado lugar a homogeneidades temáticas locales, circunscritas más a la ciudad donde los escritores actualmente viven en los Estados Unidos que su país de procedencia. En el caso de Chicago, a partir de las leyes generales y preestablecidas que trajimos del otro lado hemos empezado a describir y acatar nuestras leyes especiales, específicas de esta ciudad que nunca nos pertenecerá" (17).

9 Barry, John. "Persistencia de la memoria: prosa en español desde Chicago". Pie de página, 2, 2004, pp. 56-57. 
Considerando las limitaciones al corpus de la literatura en castellano de Chicago que delineó Barry, se puede plantear determinadas tendencias que, tal vez, podrían ser pertinentes para otras regiones norteamericanas. La primera tendencia puede denominarse como literatura de transplante ${ }^{10}$. Con escritura de transplante me refiero a una tendencia en la que los escritores, pese a vivir fuera del país de origen, no parecen haber modificado su temática ni su estilo ni sus preocupaciones. Son textos que "aparentemente" podrían haber sido elaborados en Argentina, México, o Chile, o en otros países de habla hispana y la influencia del lugar desde donde se escribe, Estados Unidos, parece ser inexistente. Enfatizo, en este caso, la condición de "aparente", porque de todas maneras en estos escritores en el acto de narrar se instala una perspectiva alejada de sus sociedades de origen, lo cual hace que la visión sobre esos universos sea diferente a la que aquel escritor que narra sobre y desde América Latina. Me imagino -y esto no dejar de ser una especulación- que en estos narradores el acto de escribir podría transformarse en un viaje de retorno a sus propias sociedades.

En la segunda tendencia se observa el peso (o la presencia) del nuevo lugar, de Estados Unidos. Obviamente, esta presencia puede expresarse de diversas formas: por ejemplo, a través de la nostalgia y recuerdos sobre el espacio de origen (en la primera tendencia no existe esta posibilidad), o por medio de la inserción de elementos del paisaje norteamericano (nombres de calles, descripción de ambientes). Se configura en esta tendencia un sujeto en un contexto que no es el suyo, pero que nunca busca indagar en cuestiones que son estrictamente propias de la sociedad norteamericana.

Finalmente, se puede distinguir una tercera tendencia de carácter transnacional cuyo rasgo principal es la construcción de un mundo y de una preocupación latina (ya no estrictamente, argentina, mexicana, o cubana, o de cualquier otro país de habla hispana), la cual solo puede

10 Tomo el término, con cierta libertad, de Darcy Ribeiro. Teoría del Brasil. México: Siglo XXI, 1975. 
existir a partir de la experiencia en Estados Unidos. Se abandonan, por tanto, las fronteras nacionales y regionales (aunque esto no significa que se borren ni desaparezcan) y se busca así reflejar un sentido de comunidad que va más allá de esos nacionalismos.

Asimismo, en la narrativa en castellano de Chicago puede distinguirse diferencias a partir de la estructura de la forma narrativa $y$, específicamente, a partir del componente del relato que resulta predominante. En tal sentido, se puede postular que la presión de un determinado referente hace que la estructura del relato adquiera ciertas modificaciones. En este caso, el referente puede ser definido como el descubrimiento, enfrentamiento y desarrollo en un universo nuevo (el norteamericano) que se manifiesta en la forma del relato de distintas maneras.

En ciertas historias, por ejemplo, el universo latino de Estados Unidos es el telón de fondo de las acciones y tal configuración del espacio adquiere una jerarquía predominante en el relato. Es un telón de fondo que, aunque parezca paradójico, no se localiza "atrás" sino en la parte más evidente (y no por eso epidérmica) de la historia. El énfasis y la jerarquía que adquiere la construcción del espacio pueden obedecer a distintas razones. Entre otras cabe mencionar, por ejemplo, el descubrimiento del nuevo territorio, la comparación entre este y el lugar de origen, como también un constante intento de apropiación del nuevo espacio a partir de la escritura. Estas posibles causas no son excluyentes entre sí. Muy por el contrario, se combinan y se alternan fluidamente.

En otros relatos es el personaje el que adquiere una mayor jerarquía semántica. Se describe un personaje que proviene de nuestros países, pero ubicado dentro del mundo norteamericano. Este personaje se caracteriza por ser un sujeto carente de un centro. Un sujeto que no tiene certeza de cuál es su lugar. Un sujeto que considera que no ha llegado a integrarse completamente al nuevo territorio en que se encuentra y que, por otro lado, asume que no pertenece a su sociedad de origen. Un sujeto que no sabe dónde está "su casa" y que, por lo tanto, posee una angustia existencial. 
En otros cuentos, el universo latino no surge a partir de la construcción de un telón de fondo ni por medio de la configuración del personaje. En estos relatos es la historia en sí misma la que expresa determinadas características del mundo latino en Estados Unidos. La historia, así, está impregnada de ese mundo. Es como si los rasgos del territorio fueran integrados en los acontecimientos que se narran. La preocupación (la inquietud del narrador o del personaje) no solo es el espacio, sino lo que sucede en ese espacio y, a su vez, ese suceder está definido por la condición de ser latino.

Hasta aquí estas reflexiones han indagado en las limitaciones del corpus de la literatura en castellano de Chicago, en determinadas tendencias, en el rol de la lengua dentro de la ciudad y su relación con esta literatura. Sin embargo, la literatura en castellano de Chicago (y por extensión de Estados Unidos) se relaciona con ciertas tradiciones literarias. Por un lado, se vincula con el proceso histórico de la producción literaria en español en los Estados Unidos, esbozado en los primeros párrafos de esta nota. Pero no solo eso. También esta producción literaria se articula con las tradiciones literarias latinoamericanas y nacionales de cada uno de los escritores que desarrolla su obra de manera orgánica en los Estados Unidos. Ese dialogo con esas tradiciones no se cierra, sino que continua con las características pertinentes y propias del acto de escribir desde Estados Unidos y deja abierta la interrogante sobre el corpus de la literatura latinoamericana. ¿Es el corpus de la literatura latinoamericana solo aquella producción que se realiza desde el Río Bravo hasta la Patagonia? ¿O debe incluirse la literatura escrita en castellano en los Estados Unidos como una parte específica de su corpus?

Asimismo, se construye una tercera inserción que merece ser enfatizada. La literatura en castellano que se produce en Estados Unidos dialoga también con las investigaciones en el campo de los Latino Studies. Cierto sector de estas investigaciones enfatiza y da mayor jerarquía a la producción literaria realizada en inglés que recrea el universo de nuestras comunidades en Estados Unidos. Por consiguiente, y en gran medida, tal sector de los Latino Studies olvida y deja fuera de su corpus de estudio la producción literaria en español. En este sentido, las antologías como las 
que publicó John Barry son una respuesta a ese sector de Latino Studies que da prioridad (y a veces exclusividad) al inglés. Y es una enfática respuesta, porque de por sí expresa y exige que el corpus de estudios de este campo deba ser no solo bilingüe, sino plurilingüe en la medida en que el mundo latino se construye de tal diversidad lingüística.

Es sintomático que las historias en español sobre el universo latino de Estados Unidos hayan sido soslayadas, e incluso olvidadas. Como se ha visto, el amplio corpus que se inicia con la llegada del conquistador Oñate recién hoy en día está siendo investigado; por otro lado, cierto sector de Latino Studies ha preferido como objeto de estudio la escritura latina en inglés, dejando de lado la producción literaria latina contemporánea en castellano. Parece ser que por distintas razones se ha tratado de no divulgar las historias escritas en español que recrean el pasado y el presente del universo latino. Si se considera que las historias -desde los mitos hasta la cinematografía, pasando por el periodismo y la novela- son elementos constitutivos de la identidad de una comunidad -tal como lo sostienen dos intelectuales con posiciones ideológicas distintas como Žižek y Vargas Llosa ${ }^{11}$-, la pregunta que surge para el caso de lo latino es preocupante. ¿Ocultar, soslayar o minimizar las historias latinas en castellano ha sido una manera de mermar la formación de una identidad? Si fuera así, chabría habido una determinada voluntad política para llevar a cabo dicho proyecto? No resulta posible responder tales interrogantes, pero conviene, al menos, dejarlas planteadas.

11 Véase el prefacio a El viaje a la ficción: El mundo de Juan Carlos Onetti. Lima: Alfaguara, 2008. Aunque Vargas Llosa no se refiere explícitamente al asunto de la identidad de la comunidad, indica claramente que el contador de historias posee la capacidad de reunir al grupo y de despertar en este sueños y deseos (15-17 pp.). Žižek, por su parte, sostiene que el rol de los poetas es fundamental para darle cohesión a los movimientos revolucionarios; es decir, para darle sentido a la actitud de un determinado grupo. También, sobre la relación entre escritura y la construcción de una identidad habría que mencionar el trabajo de Benedict Anderson. 


\section{BIBLIOGRAFÍA}

ANDERSON, Benedict. Imagined Communities: Reflections on the Origen and Spread of Nationalism. London: Verso/New Left, 1983.

ARMIJO, Ricardo. "Historia silvestre de las revistas literarias en español de Chicago". Pie de página, 1, 2002, pp. 17-27.

BARRY, John. "Escritura y escritos en español en Chicago". Contratiempo, 32, 2006, p. 8

. "Persistencia de la memoria: prosa en español desde Chicago”. Pie de página, 2, 2004, pp. 54-57.

. En el ojo del viento: ficción latina del Heartland. España: $\mathrm{s} / \mathrm{e}, \mathrm{s} / \mathrm{f}$.

CASTRO URIOSTE, José. "Más allá del fin de la historia: una conversación con Marc Zimmerman”. Pie de página, 1, 2002, pp. 3-6.

Census 2000 Data for the State of Illinois. U.S. Census Bureau 2000. Public Office. http://www.census.gov/census2000/ilihtml

MARTÍN RODRÍGUEZ, Manuel. "'Por herencia una red de agujeros': hacia una historia cultural de la literatura chicana". $L a$ Palabra y el Hombre, 124, 2002, pp. 7-24.

RIBEIRO, Darcy. Teoría del Brasil. México: Siglo XXI, 1975.

SCHIAVO, Leda. "Se nos ha muerto, como del rayo, John Barry, con quien tanto queríamos”. Contratiempo, 6, 2003, p. 23.

VARGAS LLOSA, Mario. El viaje a la ficción: El mundo de Juan Carlos Onetti. Lima: Alfaguara, 2008. 
ZIMMERMAN, Marc. "La literatura en español en Chicago". Contratiempo, 25, 2005, p. 10.

ŽIŽEK, Slavoj. Entrevista radial "Slavoj Žižek on Living in End Times”, en http://www.ttbook.org/wprplayer/popup

\section{Correspondencia:}

José Castro Urioste

Correo electrónico: castrour@calumet.purdue.edu 